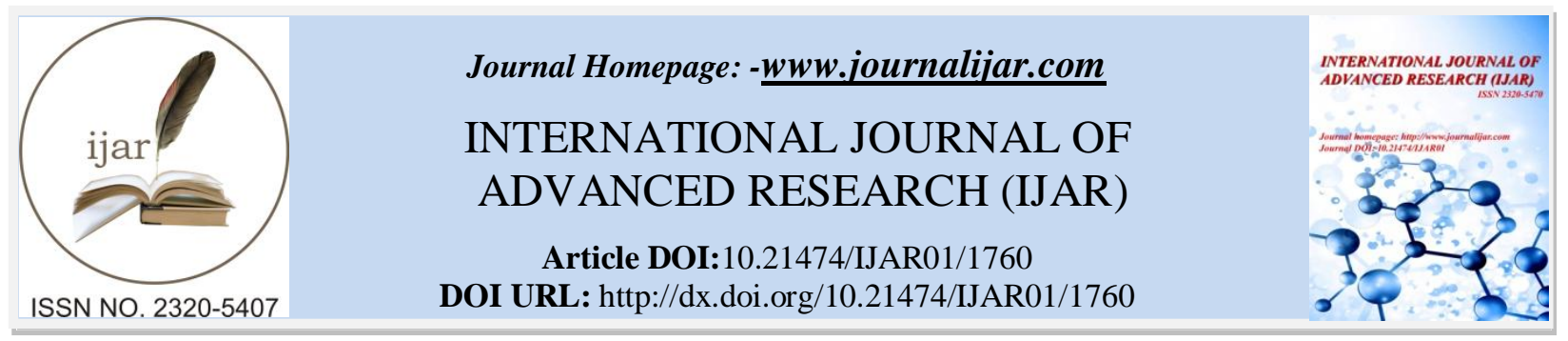

RESEARCH ARTICLE

\title{
WILL PHYSICAL EDUCATION SURVIVE IN THE PUBLIC SCHOOL ENVIRONMENT?
}

\author{
Dr. Stephen Benigno.
}

Texas A and M International University.

\section{Manuscript Info}

Manuscript History

Received: 12 August 2016

Final Accepted: 22 September 2016

Published: October 2016

\begin{abstract}
Physical Education programs have been on the decline for decades. The implementation of the 2001 No Child Left Behind legislation added new impetus to the deterioration of the programs. "Political and economic pressures on education systems to improve standardized test scores have had the unintended consequence of reducing or elimination physical education curricula" (Kohl III, Cook, 2013). In the very near future, students at the secondary level may no longer have to take a physical education course as a requirement for graduation. Requirements in some districts have been minimized to accommodate the schools in those districts that have been forced to narrow the school curriculum to address the mandated assessments and the student preparation for those assessments. Physical education requirements at the elementary level are often dictated by the philosophy of the specific school districtandmany school districts do not provide a physical education teacher at the elementary level. In addition to the minimization of the physical education programs, the physical education curriculum and instruction in many schools lacks rigor and proven instructional strategies. It may be realistic to assume that physical education will never be a viable part of the curriculum in the public school system again. This position paper will explore the justification of the physical education program in the schools and discuss some of the problems associated with the implementation of physical education at the elementary and secondary levels.
\end{abstract}

Copy Right, IJAR, 2016,. All rights reserved.

Children and young adults spend hours of their formative years in school. The schools role in the development of physical education "falls squarely within schools' long-standing tradition of providing access to health-related services such as health screening, nutrition programs, and immunizations (Kohl III, Cook 2013). Recent studies have indicated that "youth need a minimum of 60 minutes per day of vigorous- or moderate-intensity physical activity to optimize health and development" (Kohl III, Cook 2013). Unfortunately achieving 60 minutes a day of vigorous physical activity within the structure of an already taxed school curriculum is almost impossible. The Learning Centered Schedule of an elementary school must provide an opportunity for teachers to teach and students to learn, "the first and most important consideration is that the schedule maximizes instructional time and reflects curricular priorities" (Glatthorn, Jailall 2009). The instructional day has already been diminished with the addition of breakfast in the classroom and response to intervention (RTI) and enrichment activities for the gifted and talented. Additionally, the transition periods from class to class have increased in frequency with the new emphasis on the departmentalized instruction in the elementary schools. Teachers are required to move students from one classroom 
to another to address the specific academic department logistical requirements. These movements often diminish the time spent on instruction and eliminate the opportunity for elective instruction to take place.

The emphasis on the state mandated assessments have taken a toll on the physical education programs in the schools. Student performance expectations on those assessments have made it difficult for schools to provide quality physical education programs within the curriculum. Schools and administrators are required to provide more instruction and more remediation within the limitations of the school day to prepare the students for the assessments. In secondary schools, opportunities within the curriculum to provide remediation in the areas of English, math and science are at a premium. Elective course opportunities for some of the students have been eliminated. Students are often required to take remediation classes in the place of an elective. "Nearly half of school administrators report cutting significant amounts of time from physical education and recess to increase time in reading and math since passage of the NCLB Act of 2001" ( Kohl III, Cook2013) Physical education has been relegated to an afterthought.

In addition to the mandated assessment requirements. Physical education programs have also been minimized in many school districts to make room for Advanced Placement Courses and Credit Recovery Courses. The emphasis on graduation requirements and college preparation courses have had a critical impact on the physical education programs as students are often not required to take a physical education course to meet graduation requirements. Also at the secondary level, many school districts have allowed substitution activities as a replacement for physical education credit. Substitutions have included extracurricular activities, athletics, cheerleading, band or even activities sponsored away from the campus such as gymnastics or club volleyball. Most states permit schools and school districts to allow students to substitute other activities for the required physical education credit. (NASPE, 2010)

The alterations in the curriculum and the mandated assessments are just a part of the equation related to the demise of the physical education programs in the public school system. All physical education programs should have "an opportunity to learn, meaningful content, appropriate instruction, and student and program assessment” (Kohl III, Cook, 2014). Many physical education programs fall short at meeting the basic expectations and criteria of a successful physical education program. Students often do not have full access to the programs. Many of the physical education courses are not relevant to the lifestyles of the students enrolled in the courses. For many young people, their engagement with physical culture outside of school is antithetical to the physical activity experiences provided to them through their formal physical education curriculum (Macdonald, 2003). The physical education offerings within the master schedule often do not take into consideration the needs of the student. Students struggle to engage with detached pedagogies that fail to recognize their lived experiences of physical culture and often provide less challenge, responsibility, and autonomy than they are familiar with in their lives outside school (Enright, O'Sullivan 2012). The courses are often scheduled at the beginning of the day or at the end of the day. Minimum opportunities for the students to enroll in the courses often create overcrowded conditions in the classes. These conditions are not conducive to instruction or meaningful activity. There has been strong advocacy for the design of more meaningful physical education and physical activity experiences for young people (Ennis, 2000; Kretchmar, 2000). Courses in physical education at the secondary level often lack content and meaningful instruction related to that content. The balls are dispersed and free play ensues.

Teachers in self-contained elementary programs are often forced to forgo physical education instruction and replace that instruction with academic content instruction aimed at improving student performance on state mandated assessments. Recess has also been minimized to provide for more instructional time during the school day and teachers are even withholding recess to address student behavior in the classroom "One avenue schools have been taking to find time for more academics is to cut out physical education classes and recess." Another approach has been to withhold time allotted for physical activity as a punishment for poor classroom behavior, or for extra tutoring time for struggling students". (National PTA, 2006) Alabama mandates at least 30 minutes of physical education per day in grades K-5, but it does not require daily recess (NASPE 2010).Many school districts do not provide a physical education teacher at the elementary level, teachers are expected to integrate physical education instruction within the parameters of their already taxed day. Some districts provide an itinerant teacher who travels from school to school scheduling physical education classes within specific allocations of time. "It is often easier to engage students in physical education outside of the formal school and curricular context, free from chaotic school timetabling" (Hellison, 2009) Districts that do provide a physical education teacher, usually only provide one teacher per elementary school and that teacher may be responsible for teaching physical education to multiple classes and multiple grade levels. 
The physical education curriculum requirements vary from district to district and school to school. Physical Education content standards have been established in many states. Connecticut is one state that has established content standards that are specific to what students should know and be able to do by the end of the $12^{\text {th }}$ grade. The standards are written and specific to the grade levels of the students. The emphasis of the standards is on physical activity, human movement, fitness, responsible behavior, respect for differences and the benefits of physical activity. Unfortunately, the implementation of the physical education standards is limited by the statute that originated the standards. "There is no statutory or regulatory requirement for public schools to provide a set amount of time for physical education in any grade"(CSDE, 2000). The Connecticut State Department of Education goes on to stipulate that "each school district must provide a total of 20 minutes of physical exercise during the regular school day but the physical exercise does not have to occur in a physical education class"(CSDE, 2000). The legislation also stipulates that "school districts are not required to follow the state curricula and the SDE guidelines are voluntary" (CSDE, 2000 ) Graduation requirements are also specified in the statutes but to graduate from high school in the state of Connecticut, each student must only have a minimum of one credit of physical education over the four grades. One credit is defined as the equivalent of a 40 minute class each school day for one school year (CSDE, 2000)

Physical education is not the recipient of support in many school districts and states across the country. The mandated assessments are one reason for the decline in emphasis and the priorities of the state department of education are another but the programs have been deteriorating long before the NCLB legislation. During the sixties and early seventies, physical education programs were at their pinnacle of existence. Physical education teachers were well respected members and participant leaders of the faculty. Most of the physical education teachers coached and were leaders of the athletic programs in the schools. Physical education positions were plentiful and college of education programs turned out numerous candidates. The natural course of advancement for a physical education teacher was into school administration. Many of the school administrators and principals were ex-coaches. Support for physical education was undeniable.

The integration of the public school system and the passage of the Title IX legislation changed the paradigm. Predominantly white schools were integrated through mandated bussing and girls were permitted to participate in interscholastic activities. This legislation opened the door for opportunity and equality. Prior to the legislation of the seventies, most of the physical education programs catered to male students. Most of the teachers and coaches were white men. With the implementation of legislation related to Title IX and mandated integration, opportunities became available across the country for students of color and female students to actively participate in the physical education and the athletic landscape as participants, coaches and teachers. The economy and other cultural transformations also impacted the physical education programs across the country. The implementation of the Title IX legislation came at a time when the economy was in a downturn. The Vietnam War had just ended, the President of the United States had just resigned and there was disenchantment with political and social issues that were taking place in the country. Immigration from Southeast Asia and Mexico were also adding to the stress on the already exasperated educational panorama. Physical education was affected by the cultural upheaval that was beginning to manifest itself in society and in the schools. Unfortunately, the culture of the physical education hierarchy was not ready for the transformative changes that occurred.

Cultural changes in the landscape of the public school system and the inability of physical education programs to adapt to those changes have been one of the greatest contributors to the demise of the programs. In the early days of the physical education programs, students were expected to dress out for physical education and participate. After participating in the physical education activities students were provided towels, lockers and they were expected to shower and prepare for the rest of the day. Hygiene was emphasized. Students were assessed on their adherence to procedure, proficiency, knowledge and participation. Elementary teachers incorporated physical education activities into their curriculum. Part of the physical education involved dance, organized sport instruction and free recess with functional equipment and supplies that would support the activities. Students were assessed on their cooperation, participation and proficiency in the activities selected by the teachers. Teachers would actively participate and facilitate the students in their activities.

Cutbacks in funding and the changes in the student culture of the schools because of integration and immigration impacted the physical education program identity. Many teachers and coaches were unable to address the diversity and new cultural expectations of their programs. Many physical education teachers who traditionally coached and taught at the schools were no longer willing to teach and coach. Athletic teams often became sponsored by outside 
coaches and community volunteers. The traditional leadership role of the physical education teacher became diminished. This change in the physical education landscape had an effect on the physical education programs and their status in the schools and the expectations of the programs.

Today, the student requirement to shower after an activity is no longer emphasized. The instructional period in some schools does not provide enough time in the day for the students to prepare for class after an activity. Many students decide to forgo the activity and spend the period in the bleachers. Many students are from cultures that frown upon children changing clothes away from home. Many students in today's society do not feel safe taking their clothes off in front of other students. Locker rooms are often not staffed with locker room attendants and students are often left unattended in the locker rooms. The physical education curriculum is no longer what it once was. Many of the classes are overcrowded and the curriculum has been diminished to meet the needs of the masses. Individualized instruction is absent from the instructional design of the classes. Activities are often chosen by the teacher to address the interests of a few and not the majority.

Elementary teachers often fail to take into consideration the skill level of the individuals involved in the activities. Boys and girls are often assigned to play specific activities together and many of those students have limited ability or knowledge of those activities. Many of the activities at the elementary level are not age appropriate. Students at the elementary level are often forced to participate in activities that are not interesting and not challenging for the elementary student. Age appropriate activities and skill development are few and far between. Many activities in the schools without a certified Physical Education teacher provide recess opportunities for their students without any skill development, instruction or encouragement. Many times students are simply "turned loose" on the playground and minimally supervised during their activity period. The Robert Wood Johnson Foundation reported in 2007 that only $36 \%$ of children receive the recommended amount of physical activity and stress that recess time is one of the best opportunities to incorporate physical activity into a child's day.

The physical education component is a necessary content area that should be included within the curriculum of elementary and secondary schools. The argument for an inclusive and comprehensive physical education component within the curriculum is undeniable. Unfortunately the reality of the educational landscape is dictating the elimination of physical education as a mandated content area within the curriculum. There absolutely isn't enough time during the school day to provide a physical education program that meets the recommended requirements of the experts in the field. Instructional, remedial and enrichment programs to develop academic opportunities must and will supplant the existing mandated physical education programs. The social forces that influence decisions regarding curriculum development and emphasis, are requiring schools to offer more opportunities related to technological, scientific and mathematical areas of expertise. "Out of school physical activity programs also receive attention in the literature in terms of their perceived role in combating youth disaffection and antisocial behavior and their potential to lead to educational gains" (Sandford, Armour \& Warmington 2006).Opportunities for students to excel in athletics and physical education outside of the public school curriculum have continued to increase and these opportunities are becoming more accessible through programs of urban revitalization. Fitness gyms, recreation centers, athletic leagues, clubs are becoming more prevalent in most communities.

Theory, research and literature have supported the need for physical education programs that emphasize fitness and lifelong health practices. The Public Schools are not adequately funded or legislatively supported to provide a program that adheres to the recommendations of experts in physical education field. The public schools are currently providing a mediocre product that only represents a shell of the program that once existed in the schools. The physical education programs have been compromised and no longer deserve the curricular emphasis and funding of the public school system. Physical education educators must develop transformational strategies that will enhance the status of physical education within the curriculum of the public schools or the demise of physical education is inevitable. 


\section{Refrences:-}

1. Connecticut State Board of Education. Nurturing the Genius of Connecticut's students, Connecticut's Comprehensive Plan for Education 1996-2000. Hartford, CT: Connecticut State board of Education, 1997

2. Ennis, C.D. (2000) Canaries in the coal mine: Responding to disengaged students using theme-based curricula. Quest 52, 119-130

3. Enright, E., O'Sullivan, M. (2012) Producing different knowledge and producing knowledge differently: Rethinking physical education research and practice through participatory methods. Sport, Education and Society, 17 (1), 35-55

4. Glatthorn, Allan A., Jailall, Jerry M. (2009) The principal as curriculum leader. $3^{\text {rd }}$ Edition (pg. 89) Corwin Press

5. Helllison, D. (2000) Goals and strategies for teaching physical education: Linking universities and communities (pp. 31-51) Human Kinetics

6. Kohl III, Harold W., Cook Heather D. (2013) Educating the student body: Taking physical activity and physical education to school. National Academies Press

7. Kretchmar, R. (2000) Movement subcultures: Sites for meaning. Journal of Physical Education, Recreation and Dance, 71 (5) 19-24

8. Macdonald, D. (2003) Curriculum change and the post-modern world: Is the school curriculum-reform movement an anachronism? Journal of Curriculum Studies, 35, 139-149

9. National Parent Teacher Association. 2006. Recess is at risk, new campaign comes to the rescue. http://www.peacefulplaygrounds.com/pdf/right-to-recess/national-pta-recessat-risk.pdf (accessed April 24, 2013).

10. NASPE (National Association for Sport and Physical Education) and AHA (American Heart Association). 2010. Shape of the nation report: Status of physical education in the USA. Reston, VA: AAHPERD.

11. RWJF (Robert Wood Johnson Foundation). 2007. Recess rules: Why the undervalued

12. Play-time may be America's best investment for healthy kids and healthy schools.

13. Princeton, NJ: RWJF.

14. Sandford, R. A., Armour, K. M., and Warmington, P.C. (2006) Re-engaging disaffected youth through physical activity programs. British Educational Research Journal, 32, 251-271 